\title{
El Paleolítico medio cantábrico y sus relaciones con el área pirenaica *
}

\author{
Victoria Cabrera Valdés *
}

\section{INTRODUCCIÓN}

El presente trabajo tiene como objeto concretar una serie de reflexiones que desde hace tiempo teniamos en mente a lo largo de una serie de trabajos ajenos y nuestros sobre el Paleolítico Medio en la cornisa cantábrica y sus áreas vecinas, concretamente los Pirineos occidentales.

Hemos asumido este trabajo mas como una fase de meditación que como una fase de resultados concretos. En este punto se resumen investigaciones anteriores, pasos actuales y perspectivas futuras de ciertos aspectos. En este sentido aludimos a la significación de un elemento cultural determinado como los hendedores sobre lasca, que en algunos momentos del desarrollo de la investigación prehistórica se ha tomado como un fenómeno extraordinario dentro de la industria lítica, que pudiera caracterizar estas zonas en un período determinado: el musteriense dentro del contexto general del Paleolitico Medio. Por esta razón hemos intentado aqui expresar nuestros puntos de vista respecto a su valoración dentro de estos contextos y especialmente en yacimientos en cueva en la cornisa cantábrica, foco de nuestro trabajo.

\footnotetext{
- Trabajo presentado al "Congreso Internacional de Historia de los Pirineos, Cervera $1988 \%$

* Dpto. de Prehistoria e Historia Antigua, UNED.
} 


\section{PLANTEAMIENTO PREVIO DE LA DISCUSIÓN SOBRE LOS CONTEXTOS}

Las relaciones entre el Paleolítico Medio cantábrico y aquel de la zona pirenaica, especialmente la occidental, han venido estando señaladas por la similitud de determinados conjuntos líticos procedentes de yacimientos en cueva, entre los que destaca la presencia de un elemento común: el hendedor sobre lasca. F. Bordes (1953) destacó su presencia vinculada a contextos cuya tendencia era charentiense en las áreas que rodean al Golfo de Vizcaya, aislando un grupo musteriense regional: el "vasconiense". Esta facies, sin embargo, constituyó siempre un factor de discusión para otros investigadores, dentro del amplio marco de debate que ofrecen las facies en general.

Evidentemente, lo que resalta en primer lugar es lo inadecuado del término, ya que si bien los hendedores aparecen en el marco del Pais Vasco francés y Pirineos atlánticos, en la cornisa cantábrica un área de gran expansión se centra en los valles centrales que histórica y culturalmente no pueden considerarse vascos. Fuera de estas consideraciones más bien externas, creemos que es conveniente recordar algunos aspectos. F. Bordes se basó fundamentalmente en dos yacimientos: el abri Olha y la cueva del Castillo (capa 20) (Bordes 1953)

Posteriormente los análisis de Freeman en cueva Morin (Freeman 1964, Gonzalez Echegaray y Freeman 1971, 1973 y 1978) y la cueva del Pendo (Freeman en Gonzalez Echegaray et allii 1980) ampliaron este radio, creando al mismo tiempo un grado de cierta confusión. En este sentido los conjuntos que presentaban hendedores en la cornisa cantábrica (Morín y Castillo) los asimiló a un MTA peculiar. Mas tarde el mismo autor con los resultados del Pendo y reconociendo que no podian considerarse verdaderos MTA, prefirió denominarlos Musteriense Típico (algunos ricos en raederas).

En la revisión (Cabrera 1983) que hicimos de los conjuntos clásicos mas importantes con representación de hendedores que entraban dentro de la discusión del "vasconiense", pudimos observar la amplia variabilidad que mostraban las industrias "vasconienses" de Bordes, o MTA primero y Musteriense Típico después para Freeman. Determinados conjuntos además como el nivel 20 de Castillo revisado por nosotros (Cabrera 1978 y 1984) no podia encajar en un Musteriense Tipico rico en raederas, dadas las caracteristicas charentienses que muestra principalmente el Grupo II y en este caso determinado la hemos asimilado 
siempre a un charentiense evolucionado, coincidiendo en esta colección con la opinión de F. Bordes.

Con la finalidad de seguir evitando confusiones y obviar denominaciones erróneas propusimos en 1983 una salida intermedia. No pudiendo considerar las industrias con hendedores como una facies especial, dada la variabilidad del resto de los conjuntos, consideramos mas oportuno atribuir los conjuntos a los grupos musterienses que recojan en mayor grado las características de los mismos, aludiendo siempre a la presencia de estos elementos. Esto lo propusimos en mor de la variabilidad que presentan los conjuntos ya que no todos deben asociarse a un Musteriense Típico al menos en la cornisa cantábrica.

Por otro lado, en la región del Pais vasco francés aparecen trabajos recientes que asimilan los conjuntos con hendedores sobre lasca con un subtipo regional del MTA, en los que estos elementos substituyen a los bifaces (Santamaria 1984 y Chauchat 1985). En la vertiente sur de los Pirineos, en el Pais vasco español y Navarra, los hendedores aparecen documentados en yacimientos al aire libre. El contexto lítico en el que aparecen se asimila culturalmente al Achelense Superior Final y/o al Musteriense de Tradición Achelense, como es el caso del yacimiento de Murba, en Alava (Baldeón 1974), o el conjunto de Balsa de Aranzaduya en la vertiente navarra de la sierra de Urbasa (Vallespi 1971 y Barandiarán I., y Vallespi 1984).

El mundo de las facies se presenta confuso, pero en nuestra opinión no se debe incurrir en el defecto de ampliar la confusión. Mientras no lleguemos a incidir en nuevas ópticas alternativas en el estudio de las industrias y sobre todo a estudios detallados y análisis completos de los yacimientos, especialmente los excavados hace muchos años, no podremos sentar las bases de unos nuevos conceptos sobre el Paleolitico Medio. Según nos alejemos del área geográfica donde se reconocieron las facies, estas se desdibujan y se presentan como tendencias mas que como conjuntos representativos que aglutinan determinados atributos. En realidad, casi se podria expresar mejor como conjuntos de variables a los que se asocian o no elementos culturales en relación con determinadas actividades económicas (Cabrera 1988).

\section{LA SIGNIFICACIÓN DE UN ELEMENTO CULTURAL: EL HENDEDOR SOBRE LASCA}

Por lo general se atribuye al hendedor una relevancia especial, en determinados contextos, casi dándole un rango de marcador cultural/cro- 
nológico de cierta importancia. Su presencia sin embargo, se atestigua en numerosos contextos del Paleolítico Inferior y Medio en áreas que no se restringen a las regiones que bordean el Mar Cantábrico o el golfo de Vizcaya (Gascuña) y próximas.

Su presencia en los conjuntos líticos del Paleolítico Medio würmiense de yacimientos en cueva clásicos del Pirineo y la cornisa cantábrica, debemos quizá analizarla observando rasgos técnicos y de aprovisionamiento de materias primas, que nos acerquen a considerarlos como elementos abocados a actividades especificas, que por el momento desconocemos, y que pueden presentarse en conjuntos líticos diversos. Constituyen un factor mas de la cultura cuya valoración, en terminos técnicos, puede ser mas importante desde un punto de vista microrregional, en la detección de relaciones entre asentamientos y actividades realizadas en las distintas ocupaciones, sin que pueda atribuírseles una concepción extraordinaria, en el rango casi de fósil guia.

En la cornisa cantábrica los hendedores están presentes en diferentes conjuntos de tres yacimientos con estratigrafias largas del musteriense clásico: la cueva del Castillo, cueva Morín y la cueva del Pendo. Entre ellos forman un triángulo espacial, entre la bahía de Santander y el valle del rio Pas, cuya distancia máxima no supera los $25 \mathrm{Kms}$ (fig. 1).

En los tres yacimientos los hendedores sobre lasca se presentan realizados en ofita y cuarcitas de grano grueso fundamentalmente, no habiéndose detectado ninguno en silex. En estos casos, pensamos que existe una selección intencional de determinadas materias primas, cuya presencia es ocasional en el resto de los diversos conjuntos líticos. Además habría que tener en cuenta que en los casos de Castillo y Morin se encuentran muy próximos filones de ofita en un radio inferior a los $2 \mathrm{Kms}$. Sin embargo conviene hacer la observación de que en algunos ejemplares se detecta la presencia de córtex caracteristico de cantos rodados lo que pudiera implicar que el territorio de captación pudiera encontrarse también en las cuencas fluviales que atraviesan estas vetas. Conviene destacar que el factor de proximidad de las fuentes de ofita ya fue observado por el Conde de la Vega del Sella (1921) para el caso de Morin.

La interrelación cualitativa ofita/hendedor, adquiere proporciones diferentes en los tres yacimientos cantábricos: en la cueva del Pendo la ofita es exclusiva, en Morín es prioritaria $(84,61 \%)$ y en Castillo es superada por las cuarcitas de grano grueso (alcanzando en el recuento original de Breuil y Obermaier el $78,85 \%$, frente al $21,15 \%$ para la ofita).

Enlazando con el área pirenaica nos encontramos que en yacimientos en cueva de los Pirineos Atlánticos, con la misma problemática como 


\section{El Paleolítico medio cantábrico y sus relaciones con el área pirenaica}
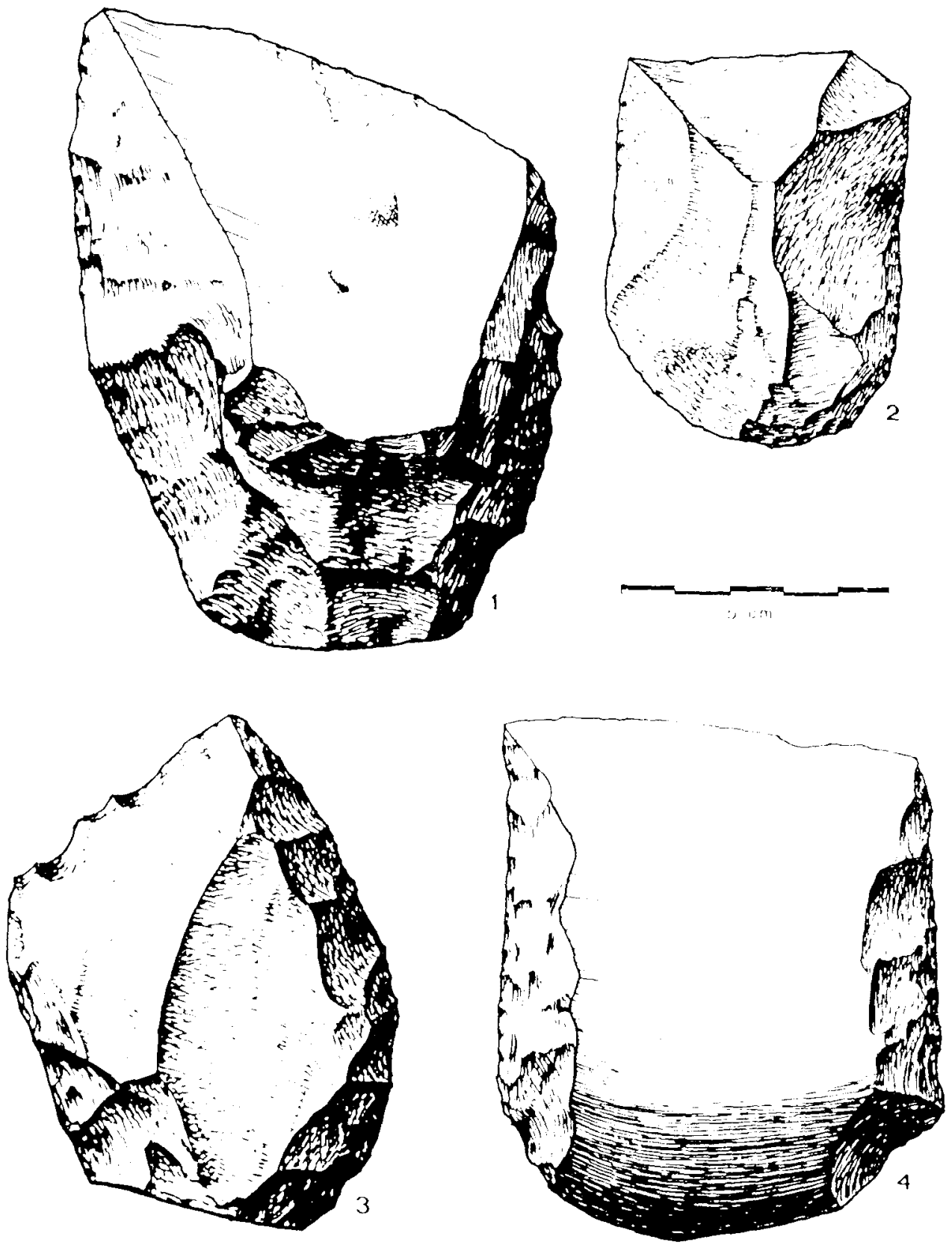

Fig. 1. Nivel 20. Hendedores (Según V. Cabrera). 
Olha, Isturitz y Gatzarria, los hendedores también se encuentran sobre materias primas mediocres para la talla, que sugiere un uso expeditivo de las fuentes mas cercanas (Bahn 1983). En el caso del abri Olha, el reciente estudio de Chauchat (1985) los hendedores sobre lasca en gres y cuarcita (grano grueso) son abundantes en las capas Fi4, representativos en Fi3 y desaparecen casi en el Fi2. Sobre cuarcitas, aparecen también en el último nivel musteriense de la secuencia de Gatzarria (Laplace 1966).

En Castillo el silex utilizado en los niveles musterienses clásicos, aparece relacionado con la manufactura de útiles cuyos módulos métricos se encuentran entre 4,5 y $7 \mathrm{cms}$, de menor talla que los hendedores. Su utilización es equilibrada en relación con la cuarcita de grano fino en las piezas de cuantificación tipológica. En los restos de talla se observa un aprovechamiento máximo de los núcleos, unido a escasas lascas siendo proporcionalmente mas importantes los fragmentos ("chunks»; Cabrera y Bernaldo de Quirós 1985), la explicación de estos datos podria estar relacionada con la necesidad de acarreo de los nódulos de esta materia prima desde zonas más alejadas y/o el tamaño de los mismos.

En las series de Morín el silex viene a ser la materia prima predominante entre las series de útiles tipológicos. En el Pendo las series de útiles tipológicos de los diferentes niveles ofrece una incidencia prioritaria clara del silex, a excepción del nivel XIII, con hendedores en ofita, en los que se equilibran los porcentajes del silex y la cuarcita.

Hasta cierto punto la selección de la ofita fundamentalmente para la realización de hendedores parece evidente en los niveles de ocupación de estos tres yacimientos. Pudiera estar vinculado con la menor capacidad volumétrica de los nódulos de silex, a lo que se une, al menos en Castillo, una necesidad de economia del mismo para determinadas piezas. La capacidad volumétrica de los cantos de cuarcitas de grano fino no parece ser tan restrictiva como en el caso del silex, si bien sus características estructurales pudieran no ser susceptibles a su transformación en lascas destinadas para las piezas en cuestión.

Otras materias primas sin embargo abundantes en el contexto de estos yacimientos quedan también relegadas en cuanto a la manufactura de hendedores aunque el volumen de los nódulos es grande y su abundancia en piezas no tipológicas atestiguan también una explotación consciente. Un ejemplo lo tendriamos en la caliza negra jurásica muy abundante entre los restos de talla en Castillo, pero que sin embargo presenta un alto grado de plasticidad que pudiera no ser apta para las funciones a las que se destinarian los hendedores. 
En cuanto al aspecto técnico de la talla de los hendedores sobre lasca de estos yacimientos ha habido algunos autores que se han especializado en este tema, como Benito del Rey. De este autor cabe destacar el análisis que realiza sobre la dirección de lascado en hendedores de estos yacimientos, especialmente Castillo y Morin.

Si observamos las características métricas, en Castillo por ejemplo, se observan tres grados: las dimensiones se encuentran (expresadas en orden longitud $\times$ anchura $\times$ espesor talón):

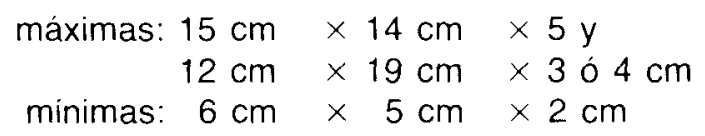

Una caracteristica especial, observada por diferentes investigadores, entre ellos Breuil y Obermaier, es la presencia de córtex en la cara dorsal, asociado al filo transversal. Este factor hace que su adscripción tipológica según la clasificación de Tixier (1956) se incluya en el tipo 0 configurando un subtitulo especial, o bien podemos aceptar la propuesta de Benito del Rey (1973) de englobarlos en un Tipo nuevo: el 8 continuando la serie establecida por el autor anteriormente citado.

El yacimiento más representativo es Castillo en el que de la colección estudiada el tipo 0 alcanza el 27 por 100 , y desligándolo como tipo 8 , el 12,2. En Morin (campaña 1969) se contabiliza una en el nivel 17 y otra en el 16. Sin embargo en las colecciones 1953/57 del Pendo no se contabiliza ninguno (fig. 1).

A pesar de este rasgo cualitativo, representativo en esta región, los tipos más representados son los que se incluyen en los tipos 2 fundamentalmente en Castillo y Morín, y el 3 exclusivo en el Pendo.

La posición estratigráfica en el grupo cantábrico se relaciona con pulsaciones finales del Würm II (Butzer 1981). En el caso de Castillo, aparecen en el final de la secuencia musteriense, la cronología relativa que Butzer propuso para la capa 20 la situaba en el Hengelo. Sin embargo, las dataciones del espectómetro de masa de $\mathrm{C} 14$ obtenidas recientemente (Cabrera y Bischof e.p.) para las capas inferiores del Paleolítico Superior Inicial, separados de la superficie de la capa 20 con hendedores por un potente nivel de limos estériles, sugieren que esta misma puede encontrarse en momentos finales del Würm II, anteriores al Hengelo y no a lo largo de esta fase como se había supuesto.

En este caso, la capa de limos estériles que señala en Castillo la transición entre el Paleolítico Medio y el Superior podría suponerse coetánea de los últimos niveles de ocupación musteriense de Morín y Pendo 
asimilados a musterienses de denticulados. De esta forma las ocupaciones musterienses que portan hendedores en las tres cuevas pueden ser contemporáneas. Este hecho, de confirmarse en el futuro mediante técnicas de datación, podría suponer una relación estrecha entre las diversas ocupaciones, importante en términos de alternancia de ocupaciones dentro de un territorio enmarcado en unos 25 kilómetros de acción.

Recapitulando, estas consideraciones realizadas sobre hendedores sobre lasca que aparecen en yacimientos en cueva asimilados en horizonte cronológicos a finales del Würm II, son indicativas de los siguientes puntos:

- Los hendedores no pueden ser considerados como fósiles guia de determinado tipo musteriense, ya que sus contextos liticos son variables. Los hendedores se encuentran en un radio muy amplio cultural/ cronológico en contextos del Paleolítico Inferior y Medio, siendo esporádicos en contextos del Paleolítico Superior.

- Sus caracteristicas morfotécnicas en distintos ámbitos reginales y distintos horizontes cronológico/culturales presentan una significación vinculada a la realización de determinadas actividades.

- Este hecho viene también señalado con una selección de materias primas, generalmente muy próximas a los yacimientos, y que en el caso del área que cubren los tres yacimientos cantábricos son relegadas prácticamente en la manufactura de otras piezas. En este caso se presentan como unos elementos culturales más dentro de su contexto, que señalan la explotación del territorio de captación de las distintas ocupaciones (fig. 2).

De confirmarse la interrelación cronoestratigráfica de los tres yacimientos en cueva, su significación como elementos de determinada funcionalidad, con parámetros morfotécnicos y explotación de materias primas semejantes, podría ser valioso en términos culturales microregionales (dentro de un horizonte cronológico/cultural delimitado por otros factores). Su valor especifico podria radicar en la posibilidad de detectar a partir del gesto técnico impreso en los elementos de la industria lítica por los individuos, la movilidad de grupos (quizá el mismo), así como la delimitación de su territorio unido a otros factores de sus contextos. 


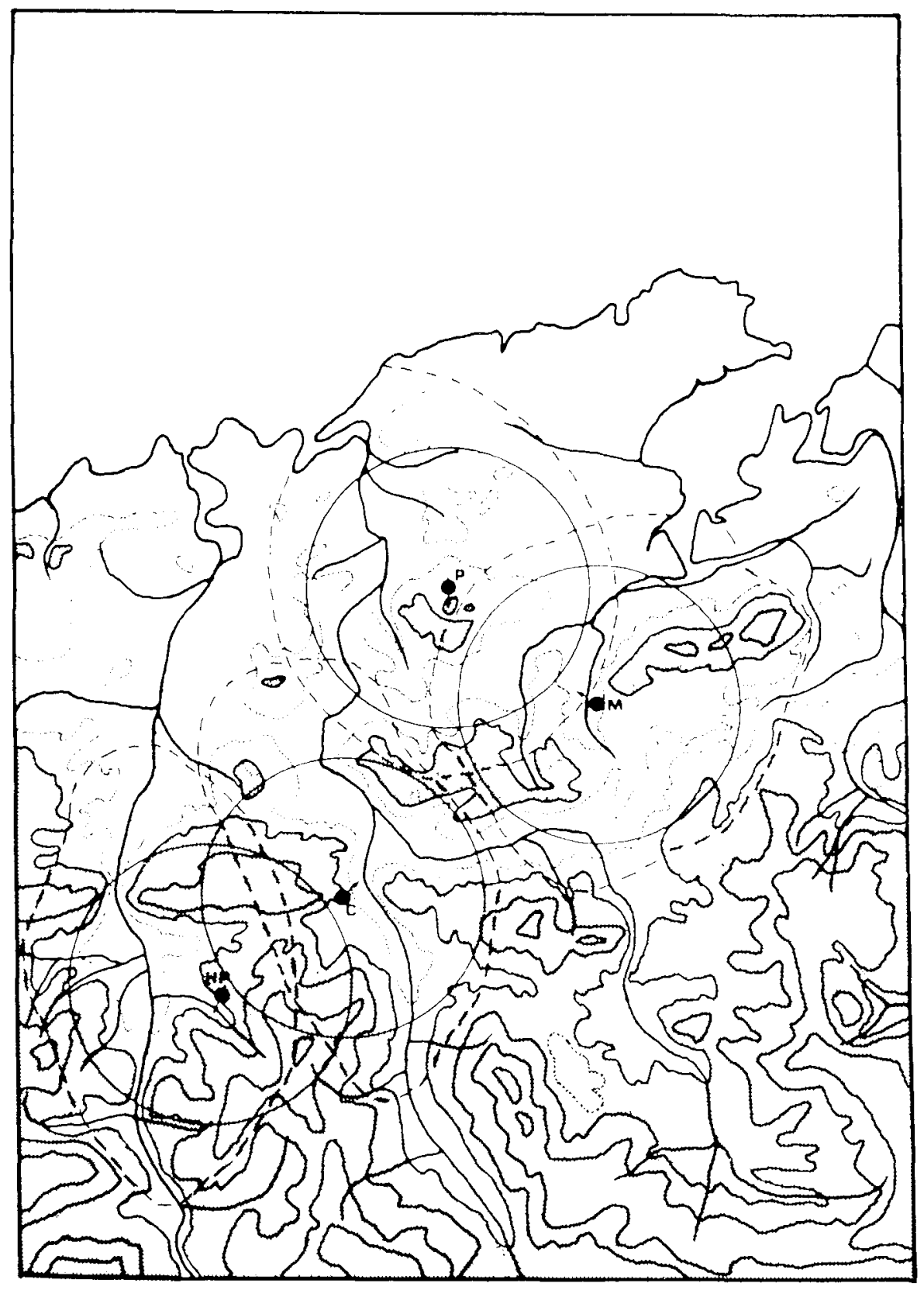

Fig. 2. Territorio (y radio de $5 \mathrm{~km}$.) de las cuevas de Pendo, Morin, Castillo y Hornos de la Peña (Según F. Bernaldo de Quirós). 


\section{BIBLIOGRAFIA}

Bahn, Paul G., 1983: Pyrenean Prehistory. Londres. Aris \& Phillips.

BALDEÓN, A., 1974: “El yacimiento del Paleolitico Inferior de Murbar»,

Estudios de Arqueología Alavesa, VI, pág. 17 y ss.

Barandiarán, I. y Vallespi, E., 1980: Prehistoria de Navarra. Pampiona. Diputación Foral de Navarra.

BENITO DEL REY, L., 1972/73: "Los hendidores de la capa musteriense 'Alpha' de la Cueva del Castillo (Santander). Estudio tipológico". Zephyrus, 23-24, pág. 269 y ss.

BORDES, F., 1953: “Essai de clasification des industries moustériennes», Bull Soc. Préhist. Française, 50, pág. 457 y ss.

BUTZER, K., 1981: "Cave sediments, Upper Pleistocene Stratigraphy and

Mousterian Facies in Cantabrian Spain. Journal of Archaeological Science, 8 pág. 133 y ss.

Cabrera, V., 1978: La cueva del Castillo (Puente Viesgo, Santander).

Estudio del yacimiento. Tesis Doctoral. Universidad Complutense.

-- 1983: “Notas sobre el musteriense cantábrico: el Ministerio de Cultura, pág. 131 y ss.

- 1984: El yacimiento de la cueva de "El Castillo" (Puente Viesgo, Santander). Bibliotheca Praehistorica Hispana, XXII, C.S.I.C.

- 1988: "Aspects of the middle Palaeolithic in Cantabrian Spain". LHomme de Neandertal 4. La Technique. Lieja. Eraul, 31, pág. 27 y SS.

Cabrera, V. y Bernaldo de Quiros, F., 1985: “Evolution technique et culturelle de la grotte de El Castillo". En OTTE M. edit. La Signification culturelle des industries lithiques. B.A.R. International Series 239, pág. 206 y ss.

CABRERA, V. y BISCHOFF. J. (en prensa): "Accelerator $14 \mathrm{C}$ ages for Basal Aurignacian at El Castillo Cave (Spain)". Journal of Archaeological Science. 
Chauchat, Cl., 1985: “L'abri Olha, Cambo (Pyrenées Atlantiques), la nouvelle étude de la collection Passemard". Bull. Soc. Préhist. Française, 82, pág. 237-8.

Freeman, L. G., 1964: Mousterian developrnents in Cantabrian Spain, Tesis doctoral. Departament of Anthropology. University of Chicago.

- 1980: Ocupaciones musterienses. En González Echegaray, J. et allii: El yacimiento de la cueva de El Pendo (excavaciones 1953-57). Bibliotheca Praehistorica Hispana XVII, pág. 29 y ss.

Gonzalez Echegaray, J. y Freeman, L. G., 1971: Cueva Morin, Excavaciones 1966-1968. Publicaciones del Patronato de las Cuevas de la Provincia de Santander.

- 1973: Cueva Morin. Excavaciones 1969. Publicaciones del Patronato de las Cuevas de la Provincia de Santander.

- 1978: Vida y muerte en cueva Morin. Institución Cultural de Cantabria. Santander.

LAPLACE, J., 1966: “Les niveaux castelperronien, protoaurignacien et aurignacien de la grotte de Gatzarria à Suhare Pays basque, fouilles 1961-1963", Quartär. 117, pág. 17 y ss.

Santamaria, R., 1984: "Les hachereaux sur éclat dans le Moustérien: les pièces du niveau p sv d'Isturitz" Bull. du Musée Basque, Bayonne.

TIXIER, J., 1956: "Les hachereaux dans l'Acheuleen nordafricain. Notes typologiques". Congrés Préhistorique de France. Poitiers-Anguleme, pág. 914 y ss.

Vega del Sella conde de LA, 1921: El Paleolítico de Cueva Morin. Notas para la Climatologia Cuaternaria. Com. de Investigaciones Prehistóricas y Paleontológicas, 29. 